\title{
The Future of Research and the Research Library
}

\author{
A Report to DEFF (Denmark's Electronic Research Library)
}

\author{
Reviewed by David Bawden
}

Hans Siggaard Jensen (2009). The Future of Research and the Research Library. København: The Lime Guild \& DEFF.

Speculations on the future of libraries are by no means new. The advent of new technologies, in particular, has led to repeated analyses and predictions as to the changes in the nature of libraries needed as a consequence. These concerns did not, by any means, arise only with the advent of the Internet, as many commentators seem to believe; indeed, they predate the general use of the digital computer, as in the example of Fremont Rider's 1994 book shows. Nor is the idea that libraries per se have passed their time of usefulness a new one; see for example Thompson (1982). The question of what libraries and librarians are for has been pursued vigorously ever since; see for example Shuman (1989) and GannonLeary, bent and Webb (2008).

It is, however, certainly true to say that the ubiquitous adoption of the Internet, and in particular the World Wide Web, with Google and Wikipedia as its main manifestations for information access, has greatly increased sense that libraries face a crisis. This is more so, when other technological trends, such as the widespread adoption of mobile devices for information access, and the blogging and social

David Bawden is Professor of Information Science, City UniversityLondon.db@soi.city.ac.uk networking phenomenon, epitomised by Facebook and Twitter, are taken into account.

The result is that we have seen, over the past decade, a proliferation of prediction and prescription, dire warnings and optimistic urgings, all giving more or less detailed advice to librarians, and their pay-masters, as to how to reform themselves in the new age. These fall into three general categories: 'journalistic' pieces, typically anecdotal and opinionated; more rigorous academic writing, based on theoretical frameworks and empirical findings; and evidencebased reports, mainly intended for managers and policy-makers.

This report is of the third kind. Written for the providers of electronic research library services in Denmark, it is firmly rooted in the contexts of that country, and seeks to offer a pragmatic way forward in providing new services. This, as we shall see, is both a strength and a weakness.

49 pages in length, it is divided into 10 brief sections, and clearly aimed a providing, and to a degree justifying, the outline of a way forward. Its first sections, after a short introduction, describe the current challenges facing research libraries in general, and the ways in which the research process itself is changing. There follows an account of the development of European university system, and its libraries, leading to summary of the current Danish situation. There follows an account of the way in which use of libraries is changing, leading to speculation 
on new roles for the library, which in turn leads to a proposed new 'culture and identity', described by the pleasing metaphor of the 'touching library'. This last section of the report arguably contains pivotal arguments of the report, and is followed by a section on the important topic of assessing the true value of the library. The remaining three sections provide outline recommendations on strategies for developing the Danish research library system, on actions by identified stakeholders, and finally on the creation of a 'dynamic roadmap' for planning and monitoring developments. The report is logically structured and clearly written for the most part, though the later sections on scenarios, stakeholders and roadmaps do tend towards abstraction and management jargon, which makes it a little difficult, at first reading, to assess what is really being said about the library situation.

The empirical basis for the report lies in a series of studies carried out in the Danish research library system: observation and analysis of the behaviour of a number of users and librarians, and individual interviews and focus groups with library practitioners and 'three centrally placed practitioners from the research library sector'. The degree of detail of, and justification for, the survey methods given here, is much less than would be required in an academic article, though it is the norm for management reports. One can therefore say only that the study seems to use the methods generally accepted as appropriate for this kind of study, and we may have reasonable confidence that it gives a good account of the views of service providers, and to an extent of library users, in the Danish context. It is the kind of study which should always be performed, but all too rarely is, before proposals for major initiatives in, or restructuring of, library services are made.

The report does not ignore the wider context in which it is set. Mention is made of worldwide developments, and some literature references are provided in support. An annex, which was not included in the draft version available to me, offers 'selected references used for further inspiration'. Nonetheless, the overall feeling of this report is that it is solidly grounded in the current Danish library context, and the attitudes of its participants. This is not a bad thing; a report of this nature would not have credibility if it were based on what is happening in the USA or in China. But it does mean that what is proposed is likely to be an incremental development of the status quo, rather than anything more revolutionary. And indeed, although the report's authors present interesting and imaginative scenarios, they do not venture near some of the more radical suggestions for library futures presented elsewhere. This has the benefit of making the report appear realistic, and likely to be acceptable to its presumed main recipients; however, it leaves the feeling that some of the more uncomfortable future scenarios for traditional libraries are ignored, rather than considered and dismissed.

The report seeks to answer three main questions:

- is there a future for the research library?

- what possible roles can the research library adopt?

- can we draw a roadmap to help us move towards the future?

Given the way in which the study has been conducted, it seems inevitable that the answers to the first and last questions would be 'yes'. Now, it seems to me that these are the indisputably correct answers, for the library world in general, and hence for the Danish situation is particular. It would, however, have been good if some more radical issues had been explicitly addressed, so that an answer of 'no' to the first question had been seriously considered.

For example, the report - correctly in my view identifies four 'sources of challenge' to the research library:

- the development of digital technology

- the development of the research system

- the development of the higher education system

- the development of the business system

It goes on to point out, accurately and clearly, some relevant issues and trends for each of these, but at a rather general level. There is, for example, no specific mention of e-science, nor of developments in digital humanities, both of which provide both challenges and opportunities to research libraries. Nor is there, in my view, adequate acknowledgement of the major changes which may be brought about by developments in open access, mediated by systems such as Google Scholar. It may reasonably be objected that a relatively short report does not allow space for mention of such points; to my mind, their coverage could profitably have replaced the rather 
elaborated discussion of the historical development of the university system, which - while certainly relevant, and giving clear background to the summary of the present Danish situation - takes up an inordinate amount of space. The general tone is of an incremental 'library business as usual' development, which seems to shy away from acknowledging some of the more profound changes which are upon us. At the end, however, two rather more radical suggestions appear, as noted later.

Considerable stress is laid on changing patterns of research, with the idea that support for innovation, understood as invention which meets with commercial success, is a 'new and important challenge' for libraries. Perhaps I am biased, having been employed as a library/information practitioner in the pharmaceutical industry, but it seems to me that this is a challenge which has been met by industrial information services since the 1930s. Other points raised in the report, for instance the need for librarians to adopt a more pro-active information provision role and to be more integrated into the user context, seem to overlook experience in these matters gained over decades in the 'information intensive industries', ad in particular in the pharmaceutical industry, which has often been a leaer in library/information matters (Bawden and Robinson 2010).

The report's first section identifies eight issues, which certainly go to the heart of the matter:

- what are user needs?

- what does the librarian do?

- who are we, who do we want to become?

- what skills do we need?

- who selects knowledge?

- which formats do we support?

- who do we partner with?

- who will pay?

The initial question, as to whether the library has a future, seems to have been implicitly answered in the positive - the issue is what kind of future. The rest of the report tries, usually in a fairly convincing way, to answer these questions in the Danish context.

There is a commendable emphasis on understanding user needs and behaviour, and the ways in which they are changing, as a basis for planning for the future. Types of users are identified, including 'indi- rect' users, who benefit from the use of libraries by other people, and those who use the library without being aware of it, for example by reading electronic journal articles by virtue of their library's subscription. The report also identifies 'the users seeking information outside the library system, searching with Google and using publicly or privately available databases and other resources'. However, it does not acknowledge the phenomenon of the non-user; someone who is entitled to use the library, and might be expected to have a need to do so, but who satisfies their need in other ways. An example, which I have myself observed, is the university student who relies entirely on course materials supplied by professors, personally owned textbooks, Google Scholar, Wikipedia, and social networking sites. Another are those students who do use their university, but not for any classical library purposes, such as reading books or journal articles; rather they use it remotely for access to course materials through the e-learning systems maintained by the library, use the library buildings as a social space, and a place for group work. We might also mention the research who relies upon systems such as ArXiv, PubMed and BioMedCentral, open access journals, and social networking interactions with peers. Although the report notes some of these phenomena, it does not really seem to recognise the need for the library to adapt to make itself relevant to this increasingly common way of working; for if it does not adapt, the answer to the report's first question is likely to negative in the long term.

On the basis of the remarks about users, the report notes three 'emerging roles' for the research library. The first is that of 'learning centre', which the report understands as the rather limited role of managing course materials for e-learning. Academic libraries in the UK and elsewhere have already gone beyond this, moving to the integration of library services, IT provision, learning support, and in some cases even the more general support services for students, such as academic and personal counselling. The second role is that of a 'virtual knowledge centre', for interdisciplinary and multi-disciplinary research; while this is certainly an interesting idea, it is difficult it understand quite what functions the report envisages such a centre undertaking. The third, and arguably most interesting, new role is that of 'catalyst for knowledge synthesis'; this sees the library taking a much more active role in knowledge creation and analysis, requiring a considerable degree of sub- 
ject expertise on the part of the library staff. This is certainly an ambitious concept. I think that while it is certainly true that we currently see librarians and information specialists taking such roles in environments such as the UK Cochrane Centre for medical information analysis (an example mentioned by the report's authors), it is only in unusual environments, such as pharmaceutical information mentioned earlier, that we find this to be task for a library/information service as a whole. Summarising this section, the report concludes - sensibly in my view - that in any real library setting development will take the form of a mix of these new roles. Although some mention is made of the changing use of the library space, particularly by students, the report does not really deal with the vital issue of what becomes of the space of the library, when its collections are mainly or wholly digital (Pomerantz and Marchionini 2007).

The report then introduces the idea of the 'touching library'; one in very close contact with the work and lives of its users. This strikes me a rather nice metaphor, and one which has not been used before; it seems preferable to most of the other English phrases used to denote the new kind of library needed in the future.

In this touching library, four new roles are envisaged for the librarian: the 'archive detective'; the 'educational sparring partner'; the 'generic knowledge expert'; and the 'co-creator'. Although there is some reflection of other writings on future roles for librarians, I think that this particular set of proposed roles in novel; it is therefore a shame that the report does not define them with greater substance and clarity.

The first of these roles is perhaps the most natural extension of the current librarian role, but expanded in the direction of having a much closer and more pro-active relationship with the users, requiring the librarian to develop good understanding of subject matter and user needs, and excellent communication skills.

The second role sees the librarian developing into a kind of educator, in partnership with teaching staff of a university. It is only briefly described in the report but experience internationally suggests that this is certainly one important direction for the academic library of the future.
The third role focuses on the need for evaluation of information quality, at a time when a main challenge is to deal with an overwhelming mass of potentially useful information. This is certainly a laudable aim, but I would echo the concerns expressed by an interviewee quoted in the report. Is it really the business of the librarian to pronounce on what is the 'best' information and knowledge in any setting ? Particularly if this judgement is expressed in a way which means that the librarian determines what information reaches the user. This is a complex issue, where the commendable desire to bring good information sources to the attention of the user can slide into the difficult area of something approaching censorship.

The fourth, and most ambitious role, is associated with the idea of the library as a clearinghouse for knowledge, and with the librarian taking an active role in the translation and synthesis of research results. It is, as the report notes, the most radical departure from current library practice; if it were to be realised, the library would be a very different place, and librarians would require a very different background and training from that which most possess, at least in the circumstances with which I am familiar.

The next section of the report deals with the important topic of the creation of value within the research library system, and with its justification to its funders and other stakeholders. While one cannot dispute the validlty of the general points made, I was surprised to see rather little about the way in which services, including the new one suggested, could be justified. Showing the value of services, preferably in quantitative terms, is emerging as a vital issue worldwide. The argument proposed that 'the public value of research libraries is measured as contribution to intrinsic value shared in a society', without an indication of how such contribution may be measured, would, I think, prove unconvincing to funders in many parts of the world; perhaps they do things differently in Denmark. The report then argues that library value in the private sector manifests in such things as time saved and increased innovation rates. Indeed. And I believe that, difficult though it may be, measurement of equivalent quantifiable benefits will be essential to justify investment in all kinds of library services in the future.

The final sections of the report take on the look and feel of management consultancy, with the presenta- 
tion of a rather complex model for a strategy roadmap, based on issues, identities, values and tensions. This leads to concrete proposals for monitoring the eight issues mentioned at the start of the report, which gives an interesting and clear appreciation of the situation. The analysis builds on the points made earlier, and concludes with identification of a 'double movement' in the development of the research. One is towards the 'local', with the library becoming more closely integrated in its user context, with its main resource being the competences of its staff, rather than its collection and physical space. The second is towards the 'global', with ubiquitous availability of information, so that 'the distinction between a library and non-library services [becomes] meaningless'. These are indeed radical proposals, and it would have been nice to see them developed and justified a little more.

I may appear to be critical of some aspects of this report. I am only able to be so, however, because the authors have provided a clear and interesting set of outline proposals for, and discussion about, the future of research libraries in their country. This will no doubt form the basis for a productive national debate about the best way forward. It would be to everyone's benefit if similar studies were carried out in other countries and contexts, as this would enable the development of library services to be more rational and more evidence-based than is usually the case.

\section{References}

Bawden, D and Robinson, L (2010). Pharmaceutical information; a 30-year perspective on the literature, Annual Reviews of Information Science and Techno$\log y$, forthcoming

Gannon-Leary, P, Bent, M and Webb, J (2008). A destination or a place of last resort? The research library of the future, its users and its librarians, $L i$ brary and Information Research, 32(101), available from http://www.lirg.org.uk/lir/ojs/index.php/lir/issue/view/6

Pomerantz, J and Marchionini, G (2007). The digital library as place, Journal of Documentation, 63(4), 505-533

Rider, F (1944). The Scholar and the Research Library: a problem and its solution, New York NY: Hadham Press

Shuman, BA (1989). The Library of the Future: alternative scenarios for the information profession, Englewood CO: Libraries Unlimited

Thompson, J (1982). The End of Libraries, London; Bingley 